\title{
Retratos do cotidiano de meninos de cinco e seis anos: a atividade de brincar
}

\author{
Flavia Bignardi da Silva Nunes ${ }^{a}$, Mirela de Oliveira Figueiredo ${ }^{b}$, \\ Patricia Carla de Souza Della Barbac ${ }^{c}$, Maria Luísa Guillaumon Emmel \\ ${ }^{a}$ Terapeuta ocupacional, Universidade Federal de São Carlos - UFSCar, São Carlos, SP, Brasil \\ ${ }^{\text {b}}$ Terapeuta ocupacional, Mestre em Saúde da Criança e do Adolescente, \\ Doutoranda em Educação Especial, Programa de Pós-graduação em Educação Especial, \\ Universidadde Federal de São Carlos - UFSCar, São Carlos, SP, Brasil \\ 'Terapeuta ocupacional, Doutora em Educação Especial, Professora adjunta do \\ Departamento de Terapia Ocupacional, Universidade Federal de São Carlos, Docente do
}

Programa de Pós-graduação em Gestão da Clínica, Universidade Federal de São Carlos - UFSCar, São Carlos, SP, Brasil

dTerapeuta ocupacional, Doutora em Psicologia, Professora associada do Departamento de Terapia Ocupacional,

Programa de Pós-graduação em Educação Especial, Programa de Pós-graduação em Terapia Ocupacional, Universidade

Federal de São Carlos - UFSCar, São Carlos, SP, Brasil

\begin{abstract}
Resumo: Introdução: As vivências do cotidiano proporcionam experiência de amadurecimento ao longo do desenvolvimento e os ambientes nos quais se inserem são fundamentais nesse processo. Tais experiências ajudam a compor a personalidade da criança e a sua forma de lidar com o mundo que a rodeia. Objetivos: descrever o comportamento ocupacional de crianças em idade pré-escolar através do relato de suas mães. Metodologia: Participaram da pesquisa quatro mães de meninos com idade entre cinco e seis anos. Os instrumentos de coleta utilizados foram um Relógio de atividades e uma entrevista semiestruturada com as mães das crianças. Com base nesses instrumentos calculou-se o tempo médio utilizado com as atividades cotidianas e foram investigadas as preferências, companhias e características emocionais do brincar, que foi utilizado como tema central de análise. Resultados: os principais resultados mostram que a maior parte do tempo diário das crianças é utilizada com sono, atividades escolares e brincadeiras. Indicam que as crianças preferem brincadeiras que desafiam aquisições que se encontram em construção. Em relação às companhias, essas crianças ainda têm a mãe como referência para o brincar, mas também pares de sua idade ou um pouco mais velhos. Conclusão: O brincar tem uma representação importante no cotidiano ocupacional das crianças e se firma como experiência de vida fundamental para a aquisição de habilidades e para o enfrentamento de desafios.
\end{abstract}

Palavras-chave: Terapia Ocupacional, Cotidiano, Desenvolvimento Infantil.

\section{Daily portraits of five and six-year old boys: the play activity}

\begin{abstract}
Introduction: Daily life experiences provide maturity along human development, and the environments in which they occur are essential for this process. These experiences help to build children's personalities and the way they deal with the world around them. Objectives: In this study, we aimed to understand the occupational behavior of four children aged five to six years old through their mothers' reports. Methodology: The average time spent with daily activities is described, and playing was a central theme of analysis. We analyzed the preferences, companies and emotional characteristics of the play activity. We used an Activity Clock and semi-structured interviews with the children's mothers as data collection instruments. Results: The main results show that most of their daily life time is spent with sleep, school and play activities. They indicate that children prefer games that
\end{abstract}

Autor para correspondência: Maria Luisa Guillaumon Emmel, Universidade Federal de São Carlos, Rod. Washington Luís, Km 235, CEP 13565-905, São Carlos, SP, Brasil, e-mail: malu@ufscar.br

Recebido em 22/4/2013; Aceito em 03/6/2013. 
challenge acquisitions that are under construction. Regarding company, these children still have their mothers as a reference to the play activity, but also peers their age or a little older. Conclusion: Play has an important representation in the daily occupational lives of these children and it stands as a key life experience to acquire skills and face challenges.

Keywords: Occupational Therapy, Daily Life, Child Development.

\section{Introdução}

A ação humana, compreendida como o conjunto de atividades que uma pessoa desempenha em seu cotidiano, compóe uma parte importante da natureza ocupacional dos seres humanos, visto que todas as pessoas têm um motivo ou necessidade de ocupação e que esta constitui um domínio específico do comportamento humano.

Wilcock (1993) considera que os seres humanos têm uma necessidade biológica de ocupaçôes: prover as necessidades de sustentação imediata do corpo, desenvolver habilidades, estruturas sociais e tecnologias voltadas para a superioridade sobre predadores e sobre o meio ambiente, exercitar e desenvolver capacidades pessoais, tornando o organismo capaz de se manter e prosperar. Para esta autora, as ocupaçôes são a fonte primária do sentido da vida e sem o engajamento nelas os seres humanos podem não permanecer saudáveis e prosperar.

Kielhofner (2008) pactua com essa visão, afirmando que a ocupação é componente da condição humana e assim como outras características próprias, os seres humanos possuem uma inata natureza ocupacional; sua característica natural é a atividade, o trabalho, a produção de alguma coisa. Segundo esse autor, a ocupação refere-se ao fazer no trabalho, no lazer ou em atividades de vida diária dentro de um contexto temporal, físico, social e cultural que caracteriza a vida humana.

A ocupação representa parte importante e significativa do ser humano, visto que todas as pessoas têm um motivo ou necessidade básica de ocupação; ela constitui um domínio específico do comportamento humano, trazendo e/ou reafirmando o sentido da vida de uma pessoa. No Brasil, os termos "ocupação" e "atividade" são entendidos muitas vezes como sinônimos dentro da terapia ocupacional, embora existam divergências quanto à amplitude da atividade e a reflexão de que as formas de ocupação podem englobar as atividades.

A natureza ocupacional do ser humano é portanto uma das especificidades de nossa espécie, que se faz notar desde muito cedo na vida e diz muito sobre as pessoas. Características pessoais se imprimem nos hábitos e nas preferências por determinadas atividades, como também na forma de desempenhá-las, de forma a poder-se muitas vezes reconhecer alguém pela maneira como faz as coisas mais do que só por suas características físicas.

Para Case-Smith (2005), as ocupaçóes definem os papéis que a criança desempenha em casa, na escola e na comunidade. O desempenho da criança em desenvolvimento deve ser visto sob o prisma da tríade indivíduo, ocupação e ambiente e é na interação entre os ambientes imediatos e nas relaçôes entre as pessoas envolvidas que a criança vivenciará papéis, relações interpessoais e atividades. Desta forma, o desenvolvimento se dá dentro de ambientes cujas características materiais e físicas são específicas e sobre as relaçôes que nele atuam e é influenciado por esse complexo de interaçóes que se dão no cotidiano da vida da criança.

As atividades do cotidiano, assim, fornecerão uma série de experiências que servirão de suporte para que seu desenvolvimento se processe; são as tramas que irão tecer seu desenvolvimento. As interações da criança com o ambiente que a circunda são imprescindíveis para o seu desenvolvimento: ela age tanto sobre esse quanto sobre as possibilidades por ele proporcionadas, expandindo o seu repertório. $\mathrm{O}$ ambiente, por sua vez, oferece acolhimento e suporte para suas açóes, muitas vezes obrigando-a a se adaptar, acomodando e auxiliando tais adaptaçóes. Nas ocupações ou atividades estão expressos os suportes, as expectativas e as limitaçóes proporcionadas pelo ambiente.

As vivências do cotidiano relacionadas ao ambiente que a criança frequenta propiciam experiências de amadurecimento durante o decorrer do desenvolvimento. Essas experiências ajudam-na a construir sua personalidade e o seu jeito de lidar com o mundo em que vive e, como o brincar é uma atividade que ocupa parte considerável de seu cotidiano, esse se faz fundamental para o seu desenvolvimento. 


\subsection{O desenvolvimento das crianças entre cinco e seis anos}

Entre os cinco e os seis anos de idade o aspecto motor geral da criança já se encontra bem desenvolvido do ponto de vista das práxis globais, ao mesmo tempo em que as estruturas mais finas estáo sendo adquiridas (PAIM, 2003).

Do ponto de vista cognitivo, a criança de cinco anos é realista e concreta, pois náo possui ainda as capacidades de abstraçáo e de desprendimento de conceitos dos adultos para se relacionar com o mundo (GESELL, 1998).

A linguagem proporciona a primeira forma de socialização à criança. Contribuem para a efetivação dela os comandos verbais de seus pais e as histórias que possuem valores culturais que lhe contam (ELY; GLEASON, 1996 apud BORGES; SALOMÂO, 2003). Piaget (1999) constatou que as crianças dessa faixa de idade já usam, na conversação, uma colaboração de pensamentos, isto é, evocam assuntos em comum para discuti-los.

Socialmente, adaptar-se à sua cultura é algo que agrada à criança de cinco anos. Todavia, ela ainda está voltada em demasia para o seu próprio mundo, razão pela qual é pouco socializada. Mesmo aos seis anos, encontra uma série de dificuldades para estabelecer relaçôes interpessoais, visto que o campo das relaçóes humanas mais complexas é algo novo para ela, sendo ela, portanto, inexperiente nele (GESELL, 1998).

As atividades de vida diária (AVD), por sua vez, oferecem oportunidades de aprendizagem das tarefas cotidianas, as quais também irão proporcionar o amadurecimento das crianças em outras esferas. Assim, atividades cotidianas como amarrar os sapatos, abotoar roupas, copiar figuras, números, objetos e letras, pintar desenhos, e se esforçar para pintá-los dentro de seus contornos, serão desenvolvidas em uma atmosfera de desafio, curiosidade e prazer pela conquista de novas habilidades motoras, cognitivas e sociais (GESELL, 1998).

\section{$1.2 \mathrm{O}$ cotidiano}

Habitualmente acredita-se que o sentido da vida é construído através de eventos importantes, atos distintivos da rotina, celebraçôes incomuns, ações únicas etc. Entretanto, esses tipos de eventos são apenas alguns pontos de suspensão do cotidiano e não têm significação se não são incluídos no conjunto de açôes e emoçóes coordenadas do nosso presente. A vida acontece, diariamente, no cotidiano.
Tomando por base a teoria de Heller (2004), pode-se dizer que o cotidiano é a vida de todo dia, que vai sendo marcada por experiências individuais, permeadas pelos contatos sociais. Essas experiências fornecerão elementos importantes para extrair do cotidiano impressões e formas que comporão o modo de agir, as preferências, os significados e a visão de mundo. Para Heller (2004), o cotidiano proporciona elementos para que a práxis aconteça. Nele, o individual e o social se processam dentro do indivíduo, transcendendo o individual e transformando as açôes humanas em representaçôes coletivas. É nesse processo que as açóes do cotidiano podem ser transformadoras.

Tornar-se adulto é possuir as habilidades que serão exigidas para viver por si próprio a vida cotidiana da sociedade na qual se está inserido. Esse amadurecimento é possibilitado pela assimilação de açôes e comportamentos e pelo ato de dominar a manipulaçáo das coisas triviais, como fazer sua refeição, e complexas, como operar sua conta bancária - os quais se dão nas vivências do cotidiano.

$\mathrm{Na}$ criança, o cotidiano é vivenciado com seus brinquedos, brincadeiras e objetos pessoais, a escola, sua professora, a família, os "amiguinhos", o quintal de sua casa, uma loja próxima de sua residência, enfim, ele se compóe dos objetos, das ocupaçóes e das relaçóes que a criança estabelece com outras pessoas em seu dia a dia. Neles, a criança está inserida por inteiro, em todas as esferas de sua vida.

É também através das atividades cotidianas que a criança experimenta o desenvolvimento de habilidades, como as sutilezas das trocas sociais, o pensamento abstrato, o exercício da musculatura fina necessária para a aprendizagem da escrita manual (ALVES, 2003).

Embora se reconheçam as singularidades e subjetividades de cada indivíduo e o quanto influenciam na construção de sua vida cotidiana, verifica-se que as crianças, assim como os adultos, organizam o seu cotidiano a partir do engajamento em atividades comuns, como o sono, atividades de vida diária, educação, cuidados com a saúde e atividades sociais, lazer e brincar, que podem apresentar variaçóes quanto ao tempo dedicado a cada uma delas e ao tipo de companhia envolvida. Tais atividades, a forma como cada criança aprende a processá-las, os ambientes que frequenta, os tipos de relaçóes que estabelece com outras pessoas (adultos e outras crianças) ao desempenhá-las, as habilidades que vai aperfeiçoando nesse processo vão cunhando a personalidade impar de cada criança, suas preferências pessoais, suas formas de ver o mundo e, consequentemente, seu desenvolvimento. 


\section{$1.3 \mathrm{O}$ brincar}

Várias horas do dia de uma criança são utilizadas com a atividade de brincar. Winnicott (1982) afirma que as crianças sentem prazer em brincar, mas que esse não é o único fator pelo qual o fazem: através das brincadeiras as crianças podem dominar angústias ou ideias e impulsos que conduzem a elas; também é por elas que serão capazes de adquirir experiência e de desenvolver sua personalidade. Aliadas a outros fatores (como, por exemplo, a religião), as brincadeiras permitem à criança unificar e integrar sua personalidade, unindo as relaçóes de sua realidade interior com a realidade exterior.

O brincar também oferece a ela a oportunidade de iniciar suas relaçóes emocionais. Entre cinco e seis anos, a criança está iniciando um período de maior contato com um círculo maior de "amiguinhos", ao mesmo tempo em que ainda tem nos membros da família o seu principal suporte. Podem brincar sozinhas sem nenhum problema, mas geralmente gostam de brincar na companhia de outros e boa parte delas estabelece uma boa relaçáo com crianças da mesma idade ou entáo com crianças um pouco mais velhas. Suas brincadeiras em grupo contam com poucos participantes e, nelas, seu maior interesse é alcançar seus objetivos individuais, não os de seu grupo (GESELL, 1998). A brincadeira permitirá a aproximação de mais crianças e o desenvolvimento das relaçôes entre elas (WINNICOTT, 1982).

A imaginação é uma constante nas brincadeiras das crianças entre três e seis anos. Elas conseguem usar de modo mais criativo os seus brinquedos e histórias simples podem ser criadas com a ajuda de fantasias, bonecos, livros de história, dente outros (FERLAND, 2006). Case-Smith (2005) aponta que, entre dois e cinco anos, as crianças são muito ativas e se envolvem frequentemente em brincadeiras grosseiras, o que se refletirá no desenvolvimento de sua coordenação motora e da percepção.

Através da grande variedade de atividades possíveis nas brincadeiras, o desenvolvimento vai se processando, modulado pela qualidade das interações envolvidas nas trocas sociais e também por suas ocupaçôes cotidianas, que trarão habilidades diferenciadas a cada criança. Nessa direção, a compreensão do brincar pode fornecer, portanto, informaçóes sobre seu desempenho ocupacional, seu desenvolvimento geral e seu desenvolvimento relacional.

\section{Objetivos}

Tendo por base esses pressupostos, o presente estudo objetivou compreender como as atividades cotidianas e o brincar se estruturam dentro da vida de crianças de cinco e seis anos de idade à luz do relato de suas mães. Para isso, identificou o tempo médio gasto com as atividades cotidianas, as preferências por brinquedos e brincadeiras, seus companheiros favoritos e o potencial dessas brincadeiras para o desenvolvimento de habilidades nas crianças.

\section{Metodologia}

Trata-se de um estudo exploratório descritivo do tipo estudo de caso múltiplo. Segundo Oliveira (2008), uma das funçóes do estudo de caso é buscar fundamentos e explicaçóes para determinado fato ou fenômeno da realidade empírica. O estudo de caso se concentra no estudo de casos considerados representativos de um conjunto de casos análogos (SEVERINO, 2007). É um método abrangente que permite chegar a generalizaçóes amplas baseadas em evidências e que facilita a compreensão da realidade. No estudo de caso múltiplo, a pesquisa utiliza mais de uma realidade para confrontar dados, visando buscar explicações e fundamentos para os fenômenos que caracterizam o objeto de estudo (OLIVEIRA, 2008).

\subsection{Participantes}

Participaram deste estudo quatro máes, que representaram seus filhos na resposta aos instrumentos de coleta de dados. As quatro crianças pertenciam a famílias de classe média de uma cidade do interior do Estado de São Paulo e foram denominadas de C1, C2, C3 e C4. Todas eram do sexo masculino, na faixa etária entre cinco e seis anos, sendo que duas delas tinham, na época da coleta, cinco anos (as crianças $\mathrm{C} 1$ e $\mathrm{C} 2$ ) e duas, seis anos de idade (as crianças C3 e C4).

\subsection{Instrumentos para a coleta de dados}

Para a presente pesquisa foram utilizados dois instrumentos, descritos sucintamente a seguir:

- Relógio de atividades: este instrumento registra o tempo médio gasto com as diversas atividades que compunham o cotidiano das crianças estudadas, tais como: sono, alimentação, autocuidado e higiene, atividades escolares, e 
brincar (EMMEL et al., 2002). Para análise dos dados desse instrumento, foi somada a quantidade de tempo utilizado por todas as crianças em cada uma das atividades e extraída a média de tempo empregada de forma geral em cada uma das atividades avaliadas.

- Roteiro de entrevista semiestruturada: foi construído um roteiro com a finalidade de coletar os dados especialmente para esta pesquisa, cuja elaboração foi baseada em Ferland (2006) e que englobou questóes sobre a vivência lúdica de crianças de cinco e seis anos, buscando identificar os tipos de brinquedos e de brincadeiras preferidos e as características do brincar de cada uma delas. Antes da aplicaçáo definitiva, o roteiro foi aplicado a uma amostra aleatória de 3 crianças da mesma faixa etária dos sujeitos da pesquisa. Tal procedimento teve por objetivo ajustar o roteiro à população estudada.

\subsection{Procedimentos para análise dos dados}

Para a análise do Relógio de atividades foi calculada a média de horas diárias de cada atividade nele especificada. A entrevista sofreu análise qualitativa, através da eleição de categorias de respostas.

\subsection{Aspectos éticos}

A pesquisa que deu origem a este artigo seguiu os procedimentos éticos da Resolução 196 e Esta pesquisa foi aprovada pelo Comitê de Ética em Pesquisa do Centro Universitário Central Paulista - UNICEP, Parecer n. 030/2011. Todas as participantes assinaram o Termo de Consentimento Livre e Esclarecido.

\section{Resultados}

A análise dos resultados desta pesquisa proporcionou a compreensão de como é composto o cotidiano dessas crianças, sua rotina e o tempo utilizado com as atividades do seu dia a dia. Como complementação, foi analisada a atividade mais representativa do cotidiano delas, o brincar, apontando suas preferências, as capacidades emocionais e relacionais do brincar e o potencial dessas brincadeiras para o desenvolvimento de habilidades.

\subsection{O tempo do cotidiano}

O cotidiano é marcado pelo tempo aplicado nas diversas atividades que acompanham a rotina de vida da criança. Para ela, as atividades são sinalizadoras do período do dia, de forma que o tempo é marcado mais pelas atividades do que pelo relógio. Assim, as brincadeiras, as atividades de vida diária (a hora do almoço, a hora do banho etc.) e os programas de TV que assiste são sinalizadores do tempo de cada dia e servem, portanto, como orientação temporal para a criança. Tais marcadores se expressam, por exemplo, como: "depois do programa X é hora de dormir", "depois do almoço você vai para a escola".

Neste estudo, o tempo das atividades do cotidiano foi investigado através do instrumento Relógio de atividades que, pontuando a média de tempo gasto em diversas atividades, pôde fornecer uma estimativa da vida corrente dessas crianças. O que se depreende da análise do Relógio de atividades é que grande parte do dia é gasto nas atividades de sono, escolares e no brincar. A Tabela 1 ilustra essa afirmação.

Como esperado, o sono é a atividade que mais ocupa tempo no cotidiano das crianças (diferente dos adultos que, em geral, dormem menos), seguido de atividades escolares, brincar, alimentação e higiene.

Chamou atenção a diferença apontada nas respostas das máes quanto ao tempo gasto com as brincadeiras nos dois instrumentos. $\mathrm{Na}$ entrevista havia também uma questão a respeito, sendo que a média de horas com a atividade de brincar nela informada foi de 3 horas e 57 minutos ao invés das 5 horas e 50 minutos registradas no Relógio de atividades. Mesmo que as respostas tenham indicado períodos de tempo diferentes nesses dois instrumentos, ainda assim são inferiores aos obtidos nas outras duas atividades (sono e escolares).

A imprecisão das mães quanto ao tempo que seus filhos passam brincado pode sugerir que essa talvez não seja a atividade priorizada no cotidiano dessas crianças pela família. Na cultura brasileira, a brincadeira não é uma atividade para a qual se dá muita importância e a maioria das famílias ignora

Tabela 1. Média de tempo utilizado por C1, C2, C3 e C4 com as principais atividades do cotidiano (média diária) no instrumento Relógio de atividades.

\begin{tabular}{cccccc}
\hline Atividade & Sono & Atividades escolares & Brincar & Alimentação & Higiene \\
\hline Tempo & $10 \mathrm{~h} 30 \mathrm{~m}$ & $8 \mathrm{~h} 50 \mathrm{~m}$ & $5 \mathrm{~h} 50 \mathrm{~m}$ & $1 \mathrm{~h} 15 \mathrm{~min}$ & $45 \mathrm{~min}$ \\
\hline
\end{tabular}


seu potencial para o desenvolvimento de habilidades motoras, cognitivas, sociais e emocionais. Já com a escola é diferente: mesmo tratando-se de crianças bem novas, entre cinco e seis anos, a escola já tem uma representatividade forte como instituição na cultura da sociedade moderna e essa sim é, desde cedo, muito valorizada na educação dos filhos, equivalendo ao valor do trabalho para os adultos.

É preciso considerar ainda que, mesmo que não tenha sido computado, dentro das atividades escolares há também um espaço de brincadeiras. Considerando essa afirmativa, decidiu-se fazer uma análise mais detalhada da atividade de brincar dessas crianças.

\subsection{Preferências no brincar}

Constatou-se uma grande diversidade de preferências por brinquedos e brincadeiras nas quatro crianças estudadas. Em relação às propriedades desses brinquedos/brincadeiras, estas foram organizadas em cinco categorias: 1 . Sensoriais; 2. Motoras; 3 . De raciocínio; 4. Simbólicas; e 5. Sociais. O Quadro 1 detalha os brinquedos e brincadeiras que foram considerados dentro dessas categorias.

Os principais estímulos envolvidos nas brincadeiras dessas crianças são os sonoros, visuais, táteis, motores, estímulos para a imaginação e para a interação com outras pessoas. Os brinquedos preferidos não denotam, nessa amostra de meninos, nenhum indício de tipificação sexual.

C1 possui praticamente a mesma quantidade de brinquedos de cada uma das cinco categorias encontradas. C4 também se encontra nesta condiçấo, porém, com uma ligeira predominância de brinquedos que estimulam a atividade simbólica e o raciocínio. Os brinquedos de C2 são, em maioria, aqueles que estimulam as habilidades motoras. Foi constatado que $\mathrm{C} 3$ possui mais brinquedos que estimulam o raciocínio e as habilidades motoras do que brinquedos que estimulam brincadeiras simbólicas.
As crianças estudadas brincam com materiais de diferentes texturas (por exemplo: giz, sabão, massa de pão, objetos frios, terra e bolinha de massagem), sendo que a massinha de modelar é o material preferido por elas, aparecendo em todas as respostas. Em seguida, presente em três respostas, está o uso da água. Areia aparece em brincadeiras de três das quatro crianças, enquanto de C3 obteve-se a informação que ela não gosta de determinadas texturas, como terra e areia. C2 gosta dos materiais acima citados, mas não demonstra preferência por nenhum deles em especial.

A música é um estímulo sonoro do qual todas as crianças desta pesquisa gostam. Três delas mostraram gostar também de brinquedos que emitem sons (como videogames e relógios musicais) e duas gostam de bater em objetos, como latas e panelas, para produzir som.

Quanto aos estímulos visuais presentes nos brinquedos e no brincar, três crianças sentem-se atraídas por claridade e luzes (por exemplo, gostam de iluminar ambientes escuros); duas têm preferência pela cor branca e duas gostam de objetos coloridos.

Vários brinquedos e brincadeiras expressam atividades com movimento, característico da idade, mas também manuais. $\mathrm{O}$ interesse por essas atividades pode ser associado à fase escolar em que se encontram, assim como a uma maior maturidade motora e destreza manual, que se desenvolve de forma bastante refinada nesse período.

Andar de bicicleta e bola são estímulos motores para a locomoção presentes em $100 \%$ das respostas (outros estímulos, presentes em brinquedos como moto elétrica, skate, carrinho e em brincadeiras de pique e danças, aparecem isoladamente nas respostas). Também apresentam acentuado interesse por brincadeiras e brinquedos que lhes proporcionem estímulos vestibulares, principalmente por escorregador (todas), balanço (duas), gira-gira (duas) e gangorra (duas).

Quadro 1. Categorização dos brinquedos/brincadeiras preferidas, citada pelos participantes.

\begin{tabular}{|c|c|}
\hline $\begin{array}{l}\text { Componentes de } \\
\text { desempenho }\end{array}$ & Brinquedos/brincadeiras preferidos \\
\hline 1. Sensoriais & $\begin{array}{l}\text { Massinha, areia/terra, giz, Bolinhas de massagem, bolhas sabão, objetos luminosos, } \\
\text { lanterna, lápis de cor, objetos coloridos, música, objetos que emitem sons, extrair sons de } \\
\text { objetos, objetos gelados }\end{array}$ \\
\hline 2. Motoras & $\begin{array}{l}\text { Bicicleta, moto, carrinho de bebê, bola, skate, carrinho, dança, pique, escorregador, gira- } \\
\text { gira, balanço, gangorra }\end{array}$ \\
\hline 3. De Raciocínio & Dominó, quebra-cabeças, jogos de carta, Cara-a-cara \\
\hline 4. Imaginação & Livros, DVDs, carrinhos pequenos, bonecos, bichos de pelúcia \\
\hline 5. Interação & $\begin{array}{l}\text { Dominó, jogo da velha, videogames, pega-pega, pique, desenhar, esconde-esconde, jogos } \\
\text { com bola }\end{array}$ \\
\hline
\end{tabular}


Das brincadeiras que estimulam o raciocínio, jogar dominó e montar quebra-cabeças apareceram em duas respostas (50\%). O jogo de cartas e o jogo Cara-a-cara também estão presentes na resposta de C3, enquanto nas respostas de C4 e C1 não há menção a essa categoria.

As mães informaram que os livros (75\%), bonecos (50\%) e carrinhos $(50 \%)$ constituem os maiores estímulos para a imaginação de seus filhos.

As preferências por brincadeiras que oferecem estímulos para interação com outras pessoas foram: dominó (C2 e C4), jogo da velha (C4), pega-pega, desenhar e esconde-esconde (C2). A maioria dos brinquedos de $\mathrm{C} 3$ oferece tais estímulos, e, em C1, eles se verificam nas brincadeiras com bola, skate e nos jogos de videogame.

As brincadeiras simbólicas apareceram em três das quatro crianças (C1, C2 e C3) e todas elas relataram que esse tipo acontecia sempre com a presença de objetos que acompanhavam as açóes das crianças (carrinhos, bonecos, animais, barcos), para os quais criam histórias. C3 é a única criança que desenvolveu brincadeira simbólica sem uso de brinquedos. Brinca de super-herói e de lutar, desenvolvendo histórias para essas brincadeiras. Esse fato indica que a presença do objeto (brinquedo) ainda é importante como desencadeador do tipo de brincadeira para essas crianças. De forma geral, o conteúdo das histórias que criam provém das atividades do seu cotidiano (como, por exemplo, histórias que envolvem família ou escola) e de filmes que assistem.

\subsection{Companhias}

O universo de relações sociais da criança se faz notar a partir da atividade de brincar, uma vez que essa é, preferencialmente, livre e nela a criança pode escolher os parceiros que mais a atraem para a brincadeira. O Quadro 2 mostra os resultados desse levantamento com a amostra estudada.

Quadro 2. Companhias prediletas para brincar.

\begin{tabular}{lcccc}
\hline \multicolumn{1}{c}{ Brincante } & C1 & C2 & C3 & C4 \\
\hline Mãe & X & X & X & X \\
Pai & X & X & & \\
Avó & & & X & \\
Irmãos & & & & X \\
Sobrinha & & & & X \\
Primos & $\mathrm{X}$ & $\mathrm{X}$ & & \\
Tios & $\mathrm{X}$ & & & \\
Outras crianças & $\mathrm{X}$ & $\mathrm{X}$ & & $\mathrm{X}$ \\
\hline
\end{tabular}

Todas as crianças da pesquisa preferem brincar acompanhadas por outra pessoa, seja adulto ou criança (da mesma idade ou um pouco mais velha), embora também brinquem sozinhas. A mãe é preferência de todas as crianças estudadas. Três delas relataram a preferência também por outras crianças e três informaram o pai ou primos como companhias. Excetuando-se a criança $\mathrm{C} 1$, que prefere brincar com um círculo restrito de adultos, as demais parecem ter interaçóes com adultos e com outras crianças durante as brincadeiras. Nota-se, no entanto, que grande parte desses contatos provém de pessoas próximas.

\subsection{Características emocionais e relacionais do brincar}

A análise das características das brincadeiras citadas nas entrevistas permitiu agrupá-las em brincadeira de competição e brincadeiras lineares. As brincadeiras de competição entre crianças compreendem aquelas que se desenvolvem com a participação conjunta de um grupo de crianças, sendo que uma delas sairá vencedora. Já as brincadeiras lineares demandam a participação destacada de uma a três crianças, cujas açôes envolvem questóes de certo ou errado e de experimentaçáo. Essas brincadeiras se caracterizaram por apresentarem um ritmo contínuo, sem o objetivo final de destacar um vencedor.

Neste trabalho, C3 e C4 (50\%) mostraram preferência por brincadeiras competitivas, como pega-pega, disputas de videogame, jogos de baralho e dominó. C1 e C2 (50\%) participam tanto de brincadeiras competitivas quanto de brincadeiras não competitivas, sem mostrar preferências por um ou outro tipo. Para essas crianças (mais novas que C3 e C4), tais brincadeiras são: pega-pega, luta, esconde-esconde, apostas de corrida, entre outras. Ambas (C1 e C2) gostam de brincadeiras não competitivas, como desenhar, e $\mathrm{C} 2$ também gosta de montar quebra-cabeças.

Nota-se que a resistência a frustraçóes nas brincadeiras ainda é baixa e que as crianças ainda não conseguem elaborar soluçóes para as suas dificuldades. Três das quatro crianças $(\mathrm{C} 1, \mathrm{C} 2 \mathrm{e}$ C3) mostram sinais de irritação, podendo chegar a agredir, verbal ou fisicamente, outras crianças com quem estejam brincando. Nesses momentos, buscam ajuda dos adultos para supera-las. Duas delas conseguem se tranquilizar depois, retornando à brincadeira. Apenas uma criança $(\mathrm{C} 4)$ consegue lidar com as frustraçóes presentes no brincar: persiste e não se zanga. Observe-se que C4 é uma criança de 
seis anos que já não tem mais tanto interesse pelas atividades sensoriais e, nas brincadeiras simbólicas, é a que não necessita do objeto para executá-las, denotando um maior grau de maturidade do que as outras crianças nesse quesito.

Este estudo mostrou ainda que duas das quatro crianças $(\mathrm{C} 1$ e $\mathrm{C} 2)$ gostam que as brincadeiras aconteçam do jeito que elas querem, sendo que, delas, uma (C1) busca impor suas vontades às demais crianças (desde que mais novas que ela), demonstrando sentimentos de liderança. Quando está brincando com crianças mais velhas, C1 mostrou-se cooperativa. Já C2 costuma assumir todas as responsabilidades necessárias para o funcionamento das brincadeiras. A interação com o outro em geral é tranquila, mas a brincadeira, embora conte com a companhia do outro, ainda não tem características de brincadeira grupal (onde todos os integrantes do grupo atuam juntos para um fim comum). No geral, são cooperativas com o brincar e com as demais crianças envolvidas nas brincadeiras $(\mathrm{C} 1, \mathrm{C} 2$ e C4). Porém C2 demonstra sentir ciúmes quando alguma outra criança se envolve com seus melhores amigos durante o brincar. O ciúme que $\mathrm{C} 2$ nutre é sustentado pelas afirmaçóes de Wallon (1968), que ressalta a idade entre os três e cinco anos como a fase na qual podem se desenvolver paixóes que quanto mais dissimuladas mais angústias geram, sendo o ciúme um exemplo.

C3 (25\%) oscila entre relaçôes de cooperação e obediência a crianças mais velhas e de dominação e liderança com crianças menores.

\subsection{Habilidades presentes no brincar}

No estudo aqui apresentado, as habilidades presentes nas brincadeiras cotidianas das crianças participantes desta pesquisa envolveram destreza, marcha, coordenação visomotora e cognição. (Quadro 3)

Destreza: Todas as crianças apresentaram habilidade para pegar, soltar, empilhar e manipular objetos, abrir e fechar portas, bater com força ou delicadeza em objetos. Para realizar todas essas atividades, a função manual dessas crianças foi desenvolvida, pois são suas habilidades manuais que lhes permitem manipular os objetos. C2, C3 e C4 gostam de empilhar objetos (como blocos de construção, brinquedos de montar e peças de dominó) para fazerem construçôes (como, por exemplo, castelos).
Quadro 3. Número de crianças que demonstraram habilidades.

\begin{tabular}{lc}
\hline \multicolumn{1}{c}{ Habilidades } & Crianças \\
\hline $\begin{array}{l}\text { Pegar, soltar, empilhar e manipular } \\
\text { objetos }\end{array}$ & Todas \\
Montar construções & 3 \\
Trocas posturais e deslocamentos & Todas \\
Exploração de novos espaços & Todas \\
Manter-se sentada & Todas \\
Empurrar objetos sobre rodas & Todas \\
Transportar objetos & Todas \\
Imitar gestos simples & Todas \\
Utilizar lápis & Todas \\
Utilizar colher & Todas \\
Utilizar garfo & 3 \\
Utilizar tesoura & 3 \\
Resolver dificuldades inesperadas & 2 \\
Imaginar situações & Todas \\
Descobrir propriedades e & Todas \\
funcionamento de objetos & \\
\hline
\end{tabular}

Marcha: Todas as quatro crianças realizam trocas posturais, exploram visualmente novos espaços, deslocam-se e mantêm-se sentadas com facilidade.

O interesse pelos deslocamentos é grande, maior do que por manterem-se sentadas. Essa postura só é utilizada para realizar alguns tipos de atividades, como desenhar ou jogar dominó. Todas apresentam eficácia para locomover-se empurrando objetos sobre rodas ou transportando algum objeto para explorar fisicamente novos espaços e para abrir e fechar portas.

O interesse de todas elas por se locomover, seja empurrando ou transportando objetos, e para explorar fisicamente os ambientes é descrito como acentuado. Inclusive, das quatro crianças, duas empurram grandes objetos com rodas (C3 gosta de empurrar um carrinho de bebê que possui, C4 empurra a cadeira de rodas de seu pai).

Coordenaçáo visomotora: As habilidades para imitar gestos simples, utilizar lápis e colher estão presentes em todas as crianças. Todas usam bem a colher e três utilizam garfo para se alimentar, ou o utilizam para se alimentar com determinado tipo de comida - por exemplo, macarrão.

Quanto a utilizar lápis, o interesse de três delas é acentuado, sendo que duas demonstram destreza manual e apenas o interesse de uma delas (C3) é descrito como médio (pois, conforme relata a entrevistada responsável pela criança, ela não tem paciência para pintar desenhos, embora demonstre habilidade para pintá-los e para reproduzir letras). 
C3 também é a única criança que não manifesta nenhum interesse em usar tesoura, ao passo que as outras três nutrem acentuado interesse por tal atividade.

Cognição: A capacidade e o interesse para resolver dificuldades inesperadas foram constatados em duas das quatro crianças deste estudo (C2 e C4). C3, quando se sente frustrada, não consegue elaborar tais soluções, mas em outras ocasióes consegue fazê-lo - porém com dificuldade - e seu interesse é médio. Já a respeito de $\mathrm{C} 1$, foi respondido que ela tenta mas não consegue fazê-lo sozinha.

Todas apresentam as habilidades para imaginar situaçóes de brincadeira, expressar seus sentimentos durante elas e interagir com outros durante o brincar, ainda que C3 nem sempre goste de demonstrar o que está sentindo.

Todas as quatro crianças procuram descobrir as propriedades e o funcionamento dos objetos, associam-nos segundo suas propriedades sensoriais e combinam objetos para jogar com eficácia. C4, por exemplo, gosta de descobrir do que são feitos e três das quatro crianças procuram entender como objetos, inclusive eletrônicos, funcionam (C4 chega a desmontá-los).

\section{Discussão}

Em relação ao tempo utilizado para brincar das crianças deste estudo (crianças com desenvolvimento típico), observou-se que isso tem sido objeto de pouca preocupaçáo para os pais que, no geral, deixam para a criança determiná-lo, ainda que com coerçôes (p. ex.: "chega de brincar, menino!"). Esse resultado foi coerente com os achados nos estudos de Sousa e Emmel (2013), que apontam essa independência maior da criança nas atividades de brincar também para crianças de outra faixa de idade (sete a nove anos). No entanto, mostram diferenças no envolvimento de pais de crianças com desenvolvimento típico e crianças deficientes em relação a atividades cotidianas. Em estudo comparando o cotidiano de crianças com desenvolvimento típico e com paralisia cerebral, essas autoras identificaram como principal diferença entre os dois grupos o tempo que as crianças com paralisia cerebral gastam com as terapias e a presença do adulto em suas atividades, aspectos pouco salientados no cotidiano das crianças com desenvolvimento típico, que acabam se envolvendo mais em outras atividades, como os cuidados pessoais e o lazer, sem a necessidade da presença do adulto em todas elas.

As preferências no brincar encontradas nesta pesquisa apresentam semelhanças com os dados obtidos por Leal (2003). Em seu trabalho, familiares de crianças pré-escolares pontuaram, quando lhes foi perguntado o que suas crianças gostavam de fazer em seu tempo livre, as seguintes brincadeiras: assistir à televisão (que se relaciona a assistir filmes em DVD), jogar bola, andar de bicicleta, brincar com bonecos, jogar videogame, montar quebra-cabeças e desenhar, entre outras.

A questão das brincadeiras simbólicas no presente estudo revela que as crianças estudadas parecem ainda não ter alcançado plenamente a fase de abstração, uma vez que três das quatro estudadas apresentaram a brincadeira simbólica sempre com a utilização de objetos que as ajudavam a representar a imagem criada. Para Piaget (1967), as capacidades simbólicas das crianças começam a se desenvolver por volta dos dois anos de idade, isto é, a partir dos últimos estágios do período sensório-motor. A partir de então, as crianças se tornarão, ao longo de seu desenvolvimento, aptas a diferenciar um significador de seu significado, ou seja, conseguirão distinguir um determinado objeto da palavra (imagem ou símbolo) que o representa. Em função dessa capacidade, torna-se possível evocar situaçóes e objetos que estejam ausentes na brincadeira, desenvolvendo, assim, o brincar simbólico. Segundo Stone e Church (1969), as crianças entre dois e cinco anos de idade requerem um suporte mais fidedigno da realidade em seus brinquedos. Faz-se necessário, para elas, o uso de algum objeto ou brinquedo que se assemelhe ao objeto que elas queiram representar (ou que o seja), como, por exemplo, necessitar de um objeto semelhante a um aviáo para brincarem de aterrissar e levantar voo. Da mesma forma, conforme relatado anteriormente, os brinquedos usados por $\mathrm{C} 1, \mathrm{C} 2$ e C3 (carrinhos, bonecos de animais, barcos de brinquedo) em suas brincadeiras simbólicas são representaçóes de objetos/seres existentes, para os quais elas criam histórias que também envolvem elementos existentes na realidade e com os quais têm contato (como, por exemplo, pistas de corridas de carros), seja por meio de filmes em DVD ou por outros meios.

De acordo com Bee (1997), no que diz respeito ao desenvolvimento motor, as habilidades de manipulação despontam como marco nas crianças entre cinco e seis anos. $\mathrm{O}$ interesse das crianças estudadas por empilhar objetos foi também observado por Gesell (1998), que refere sua presença em crianças de cinco anos e meio nas brincadeiras de construção. Stone e Church (1969) pontuam que, aos cinco anos de idade, as construções erguidas por elas podem possuir certo grau de complexidade, ser equilibradas 
e até mesmo estar interligadas, sendo que às vezes podem atingir grandes alturas.

Sobre a companhia predileta para brincar, a literatura refere que o adulto serve como modelo e provê ricas brincadeiras para a criança, ajudando na aquisição de experiências de desenvolvimento. Tem ele o papel de mediar as relaçóes entre a criança e os diversos universos sociais com os quais ela interage, possibilitando que ela se constitua como indivíduo social, adotando valores, condutas, atitudes e hábitos de um grupo ou cultura específica (EMMEL, 2009). Neste sentido, a mediação da brincadeira acontece muitas vezes no ambiente de convivência familiar. Destaca-se assim a importância de se conhecer como interagem as famílias e como essa convivência evolui ao longo do tempo, pois a família não é um organismo estático. As brincadeiras e todas as experiências vivenciadas pelas crianças neste estudo são contextualizadas no movimento das relações familiares (BIASOLI-ALVES, 1997).

A busca por amigo(s) para acompanhar as brincadeiras se dá, segundo Chateau (1987), somente após os cinco anos, quando a criança não mais gostará de brincar sozinha e sentirá necessidade de envolvimento com outras crianças no brincar (oposto do que ocorria nas idades anteriores quando, mesmo que houvesse interesse em passar certo tempo com outra criança, tal necessidade não se manifestava). A criança começa a compreender as diferenças entre ela e os adultos, que seu mundo e o deles não são os mesmos, por volta dos seis ou sete anos. Nessa faixa etária pode ser contra a intromissão do adulto; entretanto, antes de chegar a essa fase, ainda não desenvolveu bem a percepção sobre tais diferenças e, mesmo que a figura do adulto evoque certa superioridade, ela o vê tão somente como uma criança de grande porte. Por esse motivo, ela procura pelo adulto e aceita sua participação na brincadeira, almejando contato com ele (CHATEAU, 1987).

O presente estudo possibilita refletir que as brincadeiras elencadas nos resultados identificam o cotidiano das crianças e famílias de determinada cultura. Assim, ainda de acordo com Biasoli-Alves (1997, p. 39), as ideias a respeito do desenvolvimento infantil devem ser contextualizadas histórica e culturalmente. "O cotidiano das crianças é dominado pelas brincadeiras, por atividades que a criança organiza num tempo grande em que ela dispóe de liberdade para criar". Tais atividades compóem o comportamento ocupacional dessas crianças, servindo como intermediárias entre a vida individual e o mundo social, em açóes transformadoras que determinam seu desenvolvimento. Assim, os resultados apresentados neste estudo são coerentes com as afirmaçôes de Pinto e Lopes (2009), para quem a brincadeira é um processo de relaçóes interindividuais que propicia à criança ter acesso ao repertório cultural próprio do ambiente que a rodeia. No momento em que brinca, a criança manipula objetos com significados e entra em contato com outras crianças e/ou adultos durante a brincadeira, seja no âmbito familiar ou em um universo ampliado em atividades infantis de creches e escolas. Tais experiências oportunizam às crianças condiçóes importantes para o processo de socialização.

As características emocionais e relacionais envolvendo frustações no brincar detectadas nesta pesquisa fundamentam-se nas pontuaçôes de Stone e Church (1969), que referem que as dificuldades sociais podem ser a razão para a ocorrência de algumas frustraçóes. Para os autores, ao término dos anos pré-escolares e desse período em diante, dificuldades como decidir quais serão os pares ou os grupos das brincadeiras ou quem assumirá qual papel nelas, por quem a criança sente antipatia e de quem gosta, dentre outras, serão as principais razóes de conflito entre elas.

Outro motivo que pode causar frustraçóes é o momento em que a brincadeira tem de ser interrompida, como constatou Leal (2003), que encontrou reaçóes de revolta e de protesto, manifestação de zanga, choro e xingamentos como respostas a tais situaçóes.

Neste sentido, a atividade lúdica favorece a emergência de sentimentos, medos e ansiedades de difícil expressão e elaboração. Em decorrência disso, constitui-se como um recurso em potencial para o enfrentamento de complicaçóes e dificuldades vividas por crianças (ANGELI; LUVIZARO; GALHEIGO, 2012).

Acerca das habilidades requeridas e estimuladas no brincar das crianças estudadas, autores apontam o brincar como forma significativa de estimulaçáo e que estimular brincando representa uma forma prazerosa de desenvolver diferentes habilidades.

Cruz e Emmel (2007) consideram o estimular como qualquer conduta direcionada à promoção do desenvolvimento infantil, independentemente de a criança apresentar alguma deficiência. Nesse sentido, estimular por meio do brincar significa fornecer oportunidades de a criança explorar e experimentar que irão requerer tanto movimentos corporais como o uso dos órgãos sensoriais, que consequentemente atuam como estímulos para o desenvolvimento de diferentes áreas, seja a motora, a cognitiva, a emocional ou a social. 
Oliveira e Francischini (2009), pautadas na perspectiva histórico-cultural, veem a brincadeira como uma atividade essencial para o desenvolvimento infantil, uma vez que atua como meio para a transição entre um estágio do desenvolvimento e outro. Por meio do brincar ocorrem importantes mudanças no desenvolvimento psíquico. Assim, para cada estágio do desenvolvimento, a brincadeira possui algo que lhe é específico.

Marques e Bichara (2011) referem que o brincar possibilita também a prática do domínio de comportamentos sociais e o aprendizado através da experimentação.

Para Emmel (1996), a partir dos quatro anos o desempenho ocupacional da criança passa por um processo de refinamento nas características motoras, maior aquisição de equilíbrio e consciência corporal em relação ao espaço físico. Com isso, a criança mostra-se muito ativa, apresentando o desejo de explorar os ambientes próximo e distante, a fim de obter detalhes, procurando entender os arredores e os limites de si mesmo, predominando atividades de corridas e saltos.

O progresso da coordenação visomotora entre os quatro e seis anos é tal que possibilita atividades que exigem um vigoroso dinamismo manual. $\mathrm{O}$ processo da escrita é intenso para a criança de seis anos, pois exige dela a combinação de uma série de aquisiçóes (os movimentos que aprendeu para usar o lápis, a reprodução de sinais e o conhecimento sobre o significado daquilo - palavra, sílaba ou letra - que irá reproduzir). Tudo isto é possível graças ao progressivo desenvolvimento do controle voluntário da criança sobre seus movimentos, tornando-se, cada vez mais, mais correto e preciso (COSTALLAT, 1978).

Por fim, o ato de brincar é, assim, imprescindível para o desenvolvimento infantil, pois através dele a criança aprende e passa a compreender a respeito do mundo que a cerca, por meio da incorporação de aspectos da realidade em seu universo de fantasias. $\mathrm{Na}$ brincadeira, vivencia aspectos do cotidiano, relaciona-se com outras crianças e/ou adultos e com isso conquista atitudes pautadas por regras e princípios morais e sociais. Desenvolve a criatividade e a inteligência, adquire autoconhecimento e conquista a sua autonomia, além da capacidade de resoluçáo de problemas (MARQUES; BICHARA, 2011).

\section{Conclusão}

Através deste estudo, considerou-se que o cotidiano é feito das açóes que acontecem no dia a dia, contextualizadas nas relaçóes individuais do sujeito com o seu meio social, buscando a transformação da realidade e o desenvolvimento pessoal. A atividade de brincar compóe parte importante do cotidiano das crianças, trazendo a elas referências fundamentais para o desenvolvimento de seu comportamento ocupacional.

Foram descritas as principais ocupaçóes que integram o cotidiano das crianças estudadas, compostas pelas atividades escolares, de brincar, alimentação e higiene, além do sono, que ocupa um bom tempo do dia. Frequentar escola ou creche faz parte do dia a dia delas e elas permanecem por mais de 5 horas diariamente nessas instituiçóes. $\mathrm{O}$ brincar se dá em determinados períodos nas escolas/ creches e também na própria casa delas.

Considerando que o brincar é uma das principais atividades de seu dia (uma vez que parte daquelas desenvolvidas na escola também envolvem o brincar), este foi analisado com mais detalhes, constatando-se que predominaram as preferências por brincadeiras motoras e competitivas, embora também estivessem presentes no cotidiano delas brincadeiras lineares. A maioria das crianças mostra-se cooperativa no brincar e estabelece uma relação pacífica com seus pares. Vê-se aqui o cotidiano compartilhado com o seu círculo de relações.

O brincar simbólico, por sua vez, geralmente se dá mediante a presença de objetos (em geral, brinquedos ou utensílios de casa) e comumente as situações criadas nesse tipo de brincadeira são baseadas em aspectos da realidade que as crianças vivenciam. Tal resultado mostra que essas crianças de cinco e seis anos ainda não dominam completamente as abstrações envolvidas nas brincadeiras simbólicas sem a presença de objetos.

Observou-se que todas gostam e buscam a presença de mais pessoas (adultos ou outras crianças) em suas brincadeiras; todavia, a maioria tem dificuldade para lidar com frustraçóes que ocorram durante o brincar e podem, inclusive, se envolver em atritos com as outras crianças. $\mathrm{O}$ adulto (especialmente as mães) é desejado como companhia de brincadeiras, exercendo um papel importante como intermediador das relaçóes da criança com o ambiente.

Os resultados desta pesquisa, embora limitados à amostra estudada, mostram ainda que as crianças preferem brincadeiras que desafiam aquisiçóes que se encontram em construção em seu corpo e mente e que tais escolhas parecem obedecer a uma necessidade de crescimento e amadurecimento de certas estruturas, contribuindo para que o desenvolvimento se processe. Embora se observe um certo padráo que norteia o 
desenvolvimento de crianças dessa faixa de idade, tais aquisiçôes, no entanto, são individuais e dependerão da história de vida de cada criança.

Os achados corroboraram dados da literatura sobre as habilidades esperadas para a idade e sobre o papel das brincadeiras e dos brinquedos do cotidiano como experiências fundamentais para a formação da personalidade e das habilidades necessárias para essas crianças enfrentarem os desafios da vida, ressaltando a relevância deles para o desenvolvimento ocupacional da criança.

\section{Referências}

ALVES, N. Cultura e cotidiano escolar. Revista Brasileira de Educação, Rio de Janeiro, n. 23, p. 62-74, 2003. Disponível em: $<$ http://www.scielo.br/scielo.php?script=sci_ arttext\&pid $=S 1413-24782003000200005 \& \operatorname{lng}=$ en\&nr $\mathrm{m}=\mathrm{iso} \& \mathrm{t} \operatorname{lng}=\mathrm{pt}>$. Acesso em: $28 \mathrm{abr}$. 2013. http://dx.doi. org/10.1590/S1413-24782003000200005

ANGELI, A. A. C.; LUVIZARO, N. A.; GALHEIGO, S. M. O cotidiano, o lúdico e as redes relacionais: a artesania do cuidar em terapia ocupacional no hospital. Interface: Comunicação, Saúde, Educação, Botucatu, v. 16, n. 40, p. 261-272, mar. 2012. http://dx.doi.org/10.1590/ S1414-32832012005000016

BEE, H. O ciclo vital. Porto Alegre: Artmed, 1997.

BIASOLI-ALVES, Z. M. M. Famílias brasileiras do século XX: os valores e as práticas de educação da criança. Temas em Psicologia, Ribeirão Preto, v. 5, n. 3, p. 33-49, 1997. Disponível em: <http://pepsic.bvsalud.org/scielo. php?pid=S1413-89X1997000300005\&script=sci_arttext $>$. Acesso em: 09 maio 2013.

BORGES, L. C.; SALOMÃO, N. M. R. Aquisição da Linguagem: considerações da perspectiva da interação social. Psicologia: Reflexáo e Crítica, Porto Alegre, v. 16, n. 02, p. 327-336, 2003. Disponível em: <http://www. scielo.br/pdf/\%0D/prc/v16n2/a13v16n2.pdf>. Acesso em: 10 mar. 2011.

CASE-SMITH, J. Occupational therapy for children. 5. ed. Missouri: Elsevier Mosby, 2005.

CHATEAU, J. O jogo e a criança. 2. ed. São Paulo: Summus Editorial, 1987.

COSTALlAT, D. M. Psicomotricidade: a coordenação visomotora e dinâmica manual da criança infradotada, método de avaliação e exercitação gradual básica. 3. ed. Porto Alegre: Globo, 1978.

CRUZ, D. M. C.; EMMEL, M. L. G. O brinquedo e o brincar na estimulaçáo manual de crianças pré escolares com deficiência física. Cadernos de Terapia Ocupacional da UFSCar, São Carlos, v. 15, n. 1, p. 7-17, 2007.

EMMEL, M. L. G. O pátio da escola: espaço de socialização. Paidéia (Ribeirão Preto), Ribeirão Preto, n. 10-11, p. 45-62, fev./ago. 1996. http://dx.doi. org/10.1590/S0103-863X1996000100004
EMMEL, M. L. G. et al. Qualidade de vida e promoçáo em saúde junto a trabalhadores: uma proposição de diagnóstico e intervençáo em terapia ocupacional. Cadernos de Terapia Ocupacional da UFSCar, Sáo Carlos, v. 10, n.1, p. 30-41, jan./jun. 2002. http://dx.doi.org/10.4322\%2Fcto.v10i1.221

EMMEL M. L. G. Proposiçôes sobre o significado e a função do brincar no desenvolvimento infantil. In: MENDES, E. G.; ALMEIDA, M. A.; WILLIAMS, L. C. A. Temas em Educação Especial: avanços recentes. Sáo Carlos: EdUFSCar, 2009. p. 85-89.

FERLAND, F. $O$ modelo lúdico: o brincar, a criança com deficiência física e a terapia ocupacional. 3. ed. Sáo Paulo: Editora Roca, 2006.

GESELL, A. A criança dos 5 aos 10 anos. 3. ed. São Paulo: Editora Martins Fontes, 1998.

HELLER, A. O cotidiano e a história. 4. ed. São Paulo: Paz e Terra, 2004.

KIELHOFNER, G. Model of Human Occupation: Theory and Application. 4nd ed. Baltimore: Lippincott Williams \& Wilkins, 2008.

LEAL, L. L. L. O brincar da criança pré-escolar: estudo de caso em uma escola municipal de educação infantil. 2003. 209 f. Tese (Doutorado em Educaçáo)-Centro de Educação e Ciências Humanas, Universidade Federal de São Carlos, São Carlos, 2003.

MARQUES, R. L.; BICHARA, I. D. Em cada lugar um brincar: reflexão evolucionista sobre universalidade e diversidade. Estudos Psicológicos, Campinas, v. 28, n. 3, 27-41, set. 2011.

OLIVEIRA, M. M. Como fazer pesquisa qualitativa. 2. ed. Petrópolis: Vozes, 2008.

OLIVEIRA, I. C. C.; FRANCISCHINI, R. Direito de brincar: as (im)possibilidades no contexto de trabalho infantil produtivo. Psico-USF, Itatiba, v. 14, n. 1, p. 59-70, jan./apr. 2009. http://dx.doi.org/10.1590/ S1413-82712009000100007

PAIM, M. C. C. Desenvolvimento motor de crianças pré-escolares entre 5 e 6 anos. Lecturas/Revista Digital, [s.l.], ano 8, n. 58, mar. 2003. Disponível em: <http:// www.efdeportes.com/efd58/5anos.htm>. Acesso em: 23 maio 2013.

PIAGET, J. Psicologia da inteligência. 2. ed. Rio de Janeiro: Fundo de Cultura, 1967.

PIAGET, J. A linguagem e o pensamento da criança. 7. ed. São Paulo: Editora Martins Fontes, 1999.

PINTO, T. O.; LOPES, M. F. Brincadeira no espaço da rua e a demarcação dos gêneros na infância. Revista Latinoamericana de Ciencias Sociales, Niñez y Juventud, Manizales, v. 7, n. 2, jul. 2009.

SEVERINO, A. J. Metodologia do trabalho cientifico. 23. ed. São Paulo: Cortez, 2007.

SOUSA, L. C.; EMMEL, M. L. G. A organizaçâo do tempo no cotidiano de crianças com paralisia cerebral e 
de crianças com o desenvolvimento típico. Temas sobre desenvolvimento, São Paulo, v. 19, n. 105, 2013. No prelo. STONE, L. J.; CHURCH, J. El preescolar de 2 a 5 años. Buenos Aires: Editorial Paidos, 1969.

WALLON, H. A evolução psicológica da criança. São Paulo: Livraria Martins Fontes, 1968. 236 p.
WILCOCK, A. A. A theory of the human need. for occupation. Journal of Occupational science, Australia, v. 1, n. 1, p. 17-24. 1993. http://dx.doi.org/10.1080/144 27591.1993.9686375

WINNICOTT, D. W. A criança e o seu mundo. 6. ed. Rio de Janeiro: Guanabara Koogan, 1982.

\section{Contribuições dos Autores}

Flavia Bignardi da Silva Nunes e Maria Luísa G. Emmel - responsáveis pela concepção, metodologia, análises, redação e revisão. Mirela de Oliveira Figueiredo e Patricia Carla Della Barba - responsáveis pelas análises, redaçáo e revisão. 